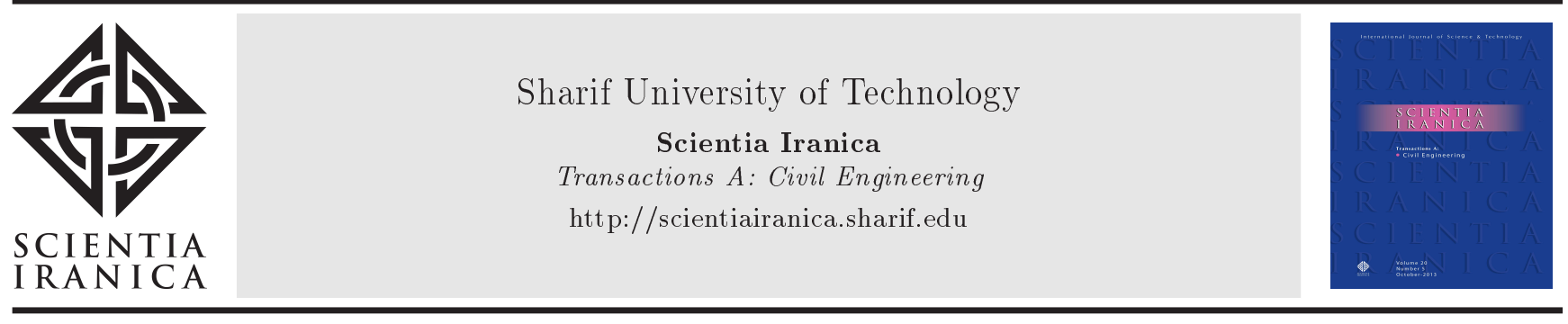

\title{
Experimental behavior of circular foundations on oil contaminated sand
}

\author{
S.A. Abtahi ${ }^{a}$ and A. Hajiani Boushehrian ${ }^{\text {b,* }}$ \\ a. Department of Civil Engineering, Estahban Branch, Islamic Azad University, Estahban, Iran. \\ b. Department of Civil Engineering, Shiraz Branch, Islamic Azad University, Shiraz, Iran.
}

Received 23 June 2017; received in revised form 21 October 2017; accepted 5 March 2018

\section{KEYWORDS}

Oil contamination;

Bearing capacity;

Load-settlement

curve;

Circular footings;

Laboratory studies;

Numerical analysis.

\begin{abstract}
This paper studies the behavior of circular footings placed on gasoil- and kerosene-contaminated soil. The ultimate objective of this study is to determine the effect of oil contamination on the sand bearing capacity. The contaminated sand layers were mixed with different levels between 1 and $4 \%$ of gasoil and kerosene contamination. This study examined the influence of the contamination depth and type of contamination. Laboratory tests were conducted on small-scale models and performed in a load-controlled manner. The results showed that the contamination could influence the load-settlement curves and lead to a reduction in its load-bearing capacity. An increase in the depth and percentage of contamination decreased the bearing capacity. Some formulas have been provided based on which one can predict the third bearing capacity factor of a circular foundation by knowing the depth and percentage of contamination.

(C) 2020 Sharif University of Technology. All rights reserved.
\end{abstract}

\section{Introduction}

Today, mankind has witnessed an increasing use of oil products in the world that produced much shedding and frequent leakage due to tanker accidents, discharges from facilities into the sea, leakage caused by drilling, and so on. The oil contamination in Kuwait during the Persian Gulf War, that in Valdes (Alaska) caused by oil tank accident, and that in Saudi Arabia due to the severe leakage of oil pipelines are examples of oil contamination through history.

In addition to the negative effects of such leakage on the environment and underground water quality, they can also change the geotechnical properties of the surrounding soil. These changes will lead to a decrease in the bearing capacity and an increase in

*. Corresponding author.

E-mail address: ahajiani@gmail.com (A. Hajiani

Boushehrian)

doi: $10.24200 /$ sci.2018.20223 the uniform or differential settlements of the nearby structural footings. There are many published papers on the subject of foundations bearing capacity. Some of these studies are focused on estimating the bearing capacity factors by analytical and numerical methods, and some others are concentrated on the determination of the foundation bearing capacity by experimental tests [1-4]. Studies on the effects of oil contamination on the foundation bearing capacity are highly limited, and most of the studies have investigated the effects of contamination on the soil geotechnical parameters. Evgin and Das (1992) conducted a number of triaxial tests on clean and motor-oil-contaminated quartz sand [5]. Al-sanad et al. (1995) and Al-sanad and Ismael (1997) conducted a number of tests to examine the effect of crude oil contamination on the geotechnical properties of a type of sand in Kuwait [6,7]. Shin et al. (1999) investigated the effects of crude oil on the shear strength parameters of a type of sand in Korea [8]. Shin and Das (2001) examined the bearing capacity of unsaturated sand contaminated soil with crude oil [9]. Based on the results, pollution led 
to a sharp drop in the sand bearing capacity. Shin et al. (2002) reported a significant decrease in the internal friction angle of the contaminated sand [10]. Khamechiyan et al. (2007) studied the effects of crude oil on the sandy soils of Bushehr in the south of Iran [11]. Nasr (2009) studied the strip foundations behavior resting on the oil contaminated soils, and showed that when the contamination percentage increased, the bearing capacity decreased and the foundation settlement increased [12]. Abousnina et al. (2015) examined engine oil contamination and its role in the fine sand geotechnical parameters [13]. Nasr (2015) presented an experimental and theoretical program aimed at promoting a greater understanding of the behavior of strip footing on oil-contaminated sand slope [14].

With the growth and development of industries, the number of factories, complexes, refineries, and oil product transportation lines around cities increases. Hence, in addition to the environmental concerns caused by the leakage and entrance of pollutions into groundwater and their side effects, the soil geotechnical characteristics and bearing capacity of soils contaminated by oil contaminations are subject to change. In such cases, the most important action to take is to revive and reform the contaminated soil. As a review of the previous research indicated, in recent decades, most studies have focused on the geotechnical properties of contaminated soils, and there is only a limited amount of information about the bearing capacity and the foundation settlement behavior. Thus, the purpose of the present study is to provide an experimental program to determine the effect of the sandy soil contamination on the bearing capacity of circular foundations. In addition, the obtained results are comprised of those collected from the uncontaminated soil.

\section{Model loading tests}

\subsection{Loading apparatus}

According to Figures 1 and 2, the apparatus used in these tests consists of a metal box of $1 \times 1 \times 1 \mathrm{~m}$ in size. A rigid frame was used to attach a pneumatic jack on top of the box. The jack uses a motor pump to apply the static force to the foundation resting on the soil. The surrounding wall was fixed to prevent the lateral deformation by means of vertical and horizontal stiffeners. One side of the box is made of a glass with a thickness of $20 \mathrm{~mm}$, which contributes to inspecting the soil placed under the foundation. The interior of the box was polished to form a smooth surface. The conditions of axial symmetry were established in all the tests. The foundation was made of a steel cylinder with a diameter of $100 \mathrm{~mm}$, a height of $50 \mathrm{~mm}$, and a total weight of $23.60 \mathrm{~N}$. All experiments were conducted such that the bottom of the foundation would be located on

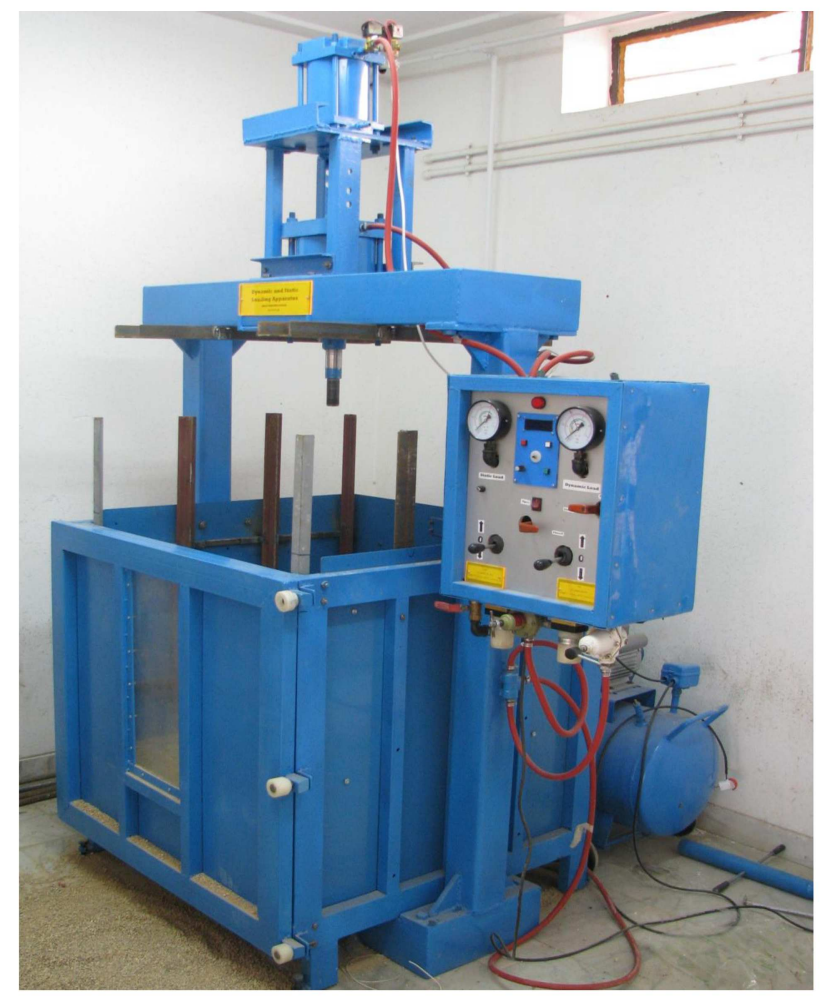

Figure 1. Complete setup with testing frame.

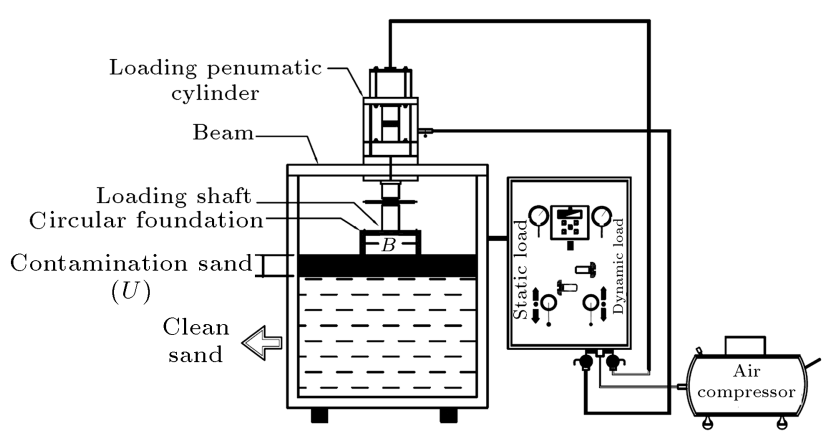

Figure 2. Schematic layout of the testing apparatus.

the soil surface. A digital gauge with an accuracy rate of $0.01 \mathrm{~mm}$ was placed on the foundation to measure its settlement. The gauge was connected to the wall of the apparatus through a magnetic base.

\section{Testing materials}

The type of soil used in this study is sandy soil and, according to the unified classification system, it is of SP type. The soil grain-size distribution curve is shown in Figure 3. The soil moisture content used during testing was kept below $1 \%$. Kerosene oil and gas oil were utilized in order to contaminate the soil. Table 1 is a summary of the basic oil properties. The soil wet density and relative density were kept between 17.5 and $18.0 \mathrm{kN} / \mathrm{m}^{3}$. The relative density of soil was also kept between 35.5 and $40 \%$. The direct shear test was 
Table 1. Oil contaminant.

\begin{tabular}{ccc}
\hline Type of oil & Density $\max (\mathrm{kg} / \mathbf{l})$ & Viscosity kinematic $\left(\mathbf{m}^{2} / \mathbf{s}\right)$ \\
\hline Kerosene & $0.820 @ 15^{\circ} \mathrm{C}$ & $2.71 * 10^{-6} @ 37.8^{\circ} \mathrm{C}$ \\
Gas oil & $0.86 @ 15^{\circ} \mathrm{C}$ & $200.0 * 10^{-6} \mathrm{~mm}^{2} / \mathrm{s} @ 37.8^{\circ} \mathrm{C}$ \\
\hline
\end{tabular}

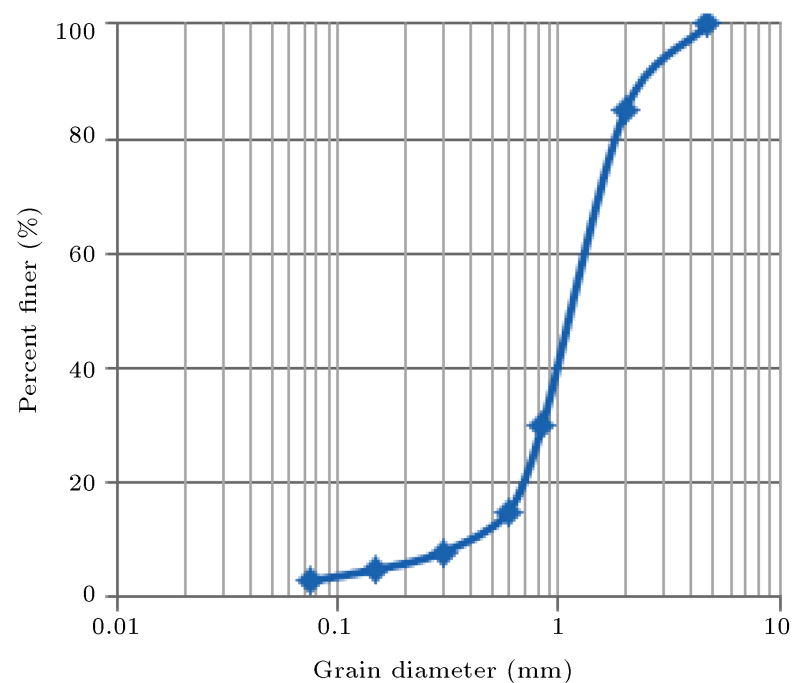

Figure 3. The grading curve of the sand.

conducted on a soil sample with the same laboratory compaction, showing an internal friction angle of 32 degrees. Some of the sandy soil characteristics are presented in Table 2.

A smooth wooden board was used with the total weight of $76.5 \mathrm{~N}$ and size of $300 \mathrm{~mm} \times 300 \mathrm{~mm}$ in order to compact each soil layer and to reach the desired density. The sand was poured in $70 \mathrm{~mm}$ layers into the box by the raining technique. After leveling the surface of each layer, the sand was compacted by tamping a smooth wooden board and dropped from selected heights a number of times based on the pollution content. For example, to gain the considered compaction for uncontaminated sand, a wooden board dropped three times from a height of $30 \mathrm{~cm}$. To

Table 2. Properties of testing sand.

\begin{tabular}{lc}
\hline \multicolumn{1}{c}{ Property } & Value \\
\hline Specific gravity $G s$ & 2.65 \\
Effective particle size, $D_{10}(\mathrm{~mm})$ & 0.40 \\
Average particle size, $D_{50}(\mathrm{~mm})$ & 1.20 \\
Uniformity coefficient, $C_{u}$ & 3.26 \\
Coefficient of curvature, $C_{c}$ & 1.36 \\
Average wet unit weight, $\gamma\left(\mathrm{kN} / \mathrm{m}^{3}\right)$ & 17.75 \\
Angle of internal friction, $\phi(\mathrm{degree})$ & 34 \\
Average relative density, $D_{r}(\%)$ & 38 \\
Maximum dry unit weight $\left(\mathrm{kN} / \mathrm{m}^{3}\right)$ & 18.78 \\
Minimum dry unit weight $\left(\mathrm{kN} / \mathrm{m}^{3}\right)$ & 16.30 \\
\hline
\end{tabular}

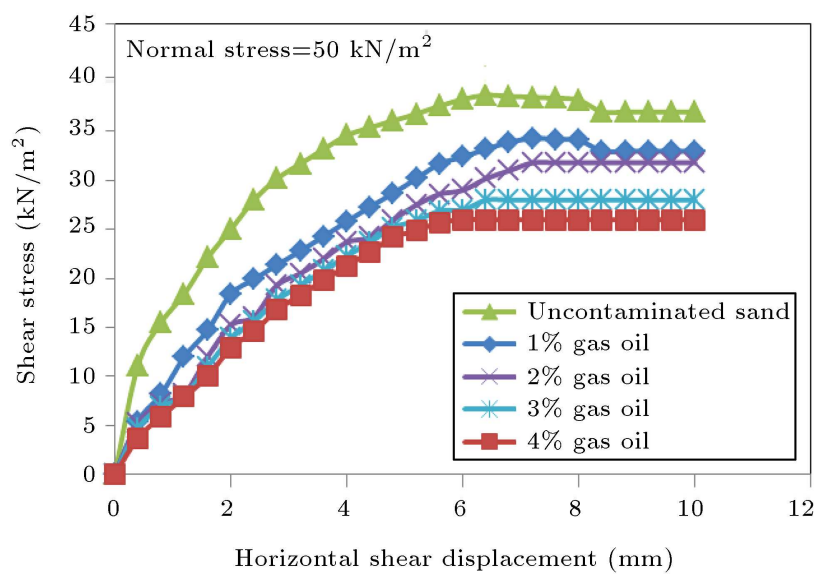

Figure 4. Variation of shear stress with horizontal displacement for gas oil contaminated sand.

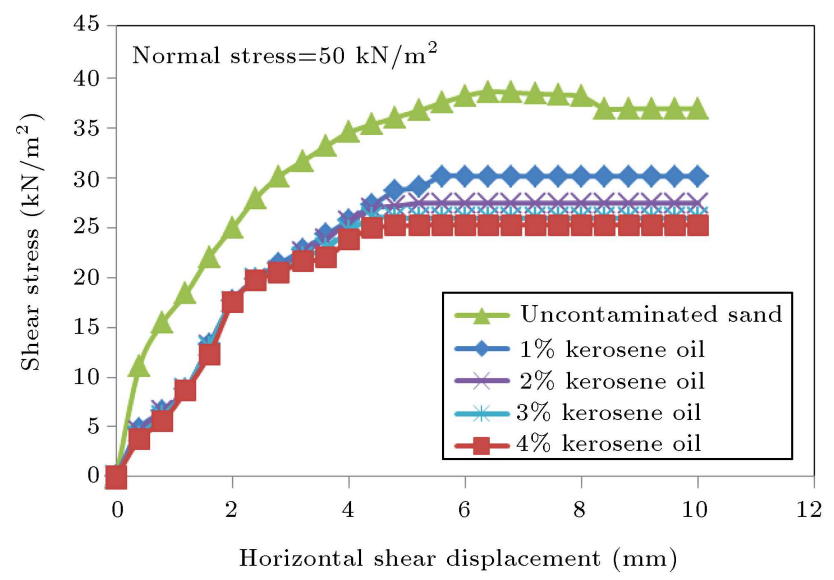

Figure 5. Variation of shear stress with horizontal displacement for kerosene oil contaminated sand.

ensure the achievement of the compaction in question, a small metal vessel with a given volume was placed randomly in different layers. The prepared surface layer was closely leveled immediately after compaction. This compaction technique may change the soil stress conditions and the type of soil from normal consolidation. The raining technique has not been utilized to compact the soil in the box, since the soil is wet and this technique cannot prepare the uniform density. A rough base has been provided for the foundation using a thin sandpaper sheet pasted on the base of foundation using special glue. Direct shear tests were conducted to determine the angle of internal friction on different percentages of soil contamination, and the results are presented in Table 3 . Figures 4 and 5 present the shear stress against normal stress for both 
Table 3. Shear strength parameters of sandy soil contaminated with gasoil and Kerosene at different percentages of contamination.

\begin{tabular}{clccc}
\hline Row & Contamination material & $\begin{array}{c}\text { Contamination } \\
\text { percentage }\end{array}$ & $\begin{array}{c}\text { Cohesion } \\
(\mathbf{k P a})\end{array}$ & $\begin{array}{c}\text { Internal friction } \\
\text { angle (degree) }\end{array}$ \\
\hline 0 & Uncontaminated sand & 0 & 5.90 & 33.00 \\
1 & Gas oil & 1 & 7.00 & 28.00 \\
2 & Gas oil & 2 & 7.24 & 27.38 \\
3 & Gas oil & 3 & 7.24 & 26.95 \\
4 & Gas oil & 4 & 7.24 & 26.00 \\
5 & Kerosene oil & 1 & 6.71 & 27.40 \\
6 & Kerosene oil & 2 & 6.71 & 26.50 \\
7 & Kerosene oil & 3 & 6.71 & 26.10 \\
8 & Kerosene oil & 4 & 6.71 & 25.60 \\
\hline
\end{tabular}

gas and kerosene oil contaminated sand. As can be seen from the results, because the sand grains are covered with higher contamination, the internal friction angle shows a smaller number. In the other form, the main reason for decreasing the internal friction angle is the lubrication of particles and a decrease in the interlocking strength. The results show that by increasing the contamination percentage, the soil internal friction angle decreases up to $21 \%$ for gas oil contamination and up to $24 \%$ for kerosene oil pollution.

\section{Laboratory program}

Laboratory testing programs include load-settlement tests on circular foundation placed on contaminated and uncontaminated sandy soil. The foundation loadsettlement curves are the raw output of the tests. The ultimate bearing capacity in a foundation can be found from the load-settlement curves, and it is selected at a point where the foundation settlement is equal to $10 \%$ of the diameter of foundation [15]. For the ease of writing the results, a parameter called Bearing Capacity Ratio (BCR) has been used, which is obtained through the following equation:

$$
B C R=\frac{q_{\text {con }}}{q_{\text {uncon }}},
$$

where $q_{\text {con }}$ and $q_{\text {uncon }}$ are the ultimate bearing capacities of the contaminated and uncontaminated soil, respectively.

The laboratory tests consist of 33 experiments in order to study the effect of contamination on the loadsettlement behavior of the circular foundation, and a summary is provided in Table 4 . As specified in the table, the varying parameters in the experiments contain the percentage, types of contamination, and depth of the contamination layer.

\section{The results of laboratory tests}

\subsection{Studying the variation in the contaminated layer thickness}

Figures 6 and 7 show the load-settlement ratio curves obtained from laboratory results in a case where contamination is equal to $2 \%$ at different contamination depth ratios $(U / B)$ equal to $0.5,1,1.5$, and 2 for a

Table 4. A summary of experimental tests conducted in the laboratory.

\begin{tabular}{cll}
\hline Series & \multicolumn{1}{c}{ Constant parameters } & Variable parameters \\
\hline CS & Test on uncontaminated sand & - \\
KO1 & Kerosene oil, percentage 1\% & $U=05 B, 1.0 B, 1.5 B, 2.0 B$ \\
KO2 & Kerosene oil, percentage $2 \%$ & $U=05 B, 1.0 B, 1.5 B, 2.0 B$ \\
KO3 & Kerosene oil, percentage $3 \%$ & $U=05 B, 1.0 B, 1.5 B, 2.0 B$ \\
KO4 & Kerosene oil, percentage $4 \%$ & $U=05 B, 1.0 B, 1.5 B, 2.0 B$ \\
GO1 & Gas oil, percentage $1 \%$ & $U=05 B, 1.0 B, 1.5 B, 2.0 B$ \\
GO2 & Gas oil, percentage $2 \%$ & $U=05 B, 1.0 B, 1.5 B, 2.0 B$ \\
GO3 & Gas oil, percentage $3 \%$ & $U=05 B, 1.0 B, 1.5 B, 2.0 B$ \\
GO4 & Gas oil, percentage $4 \%$ & $U=05 B, 1.0 B, 1.5 B, 2.0 B$ \\
\hline
\end{tabular}




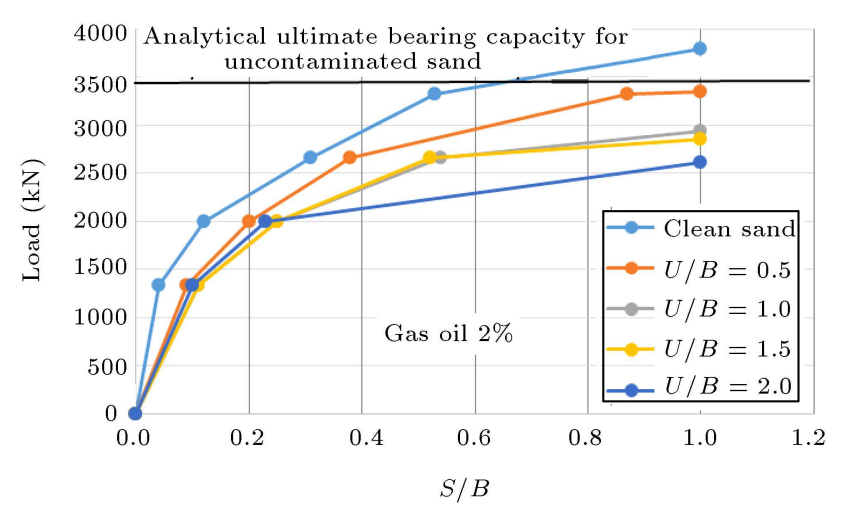

Figure 6. The load-settlement ratio curves of a circular foundation placed on a sandy soil contaminated with gasoil with different contamination depths obtained from laboratory results (contamination percentage $=2 \%$ ).

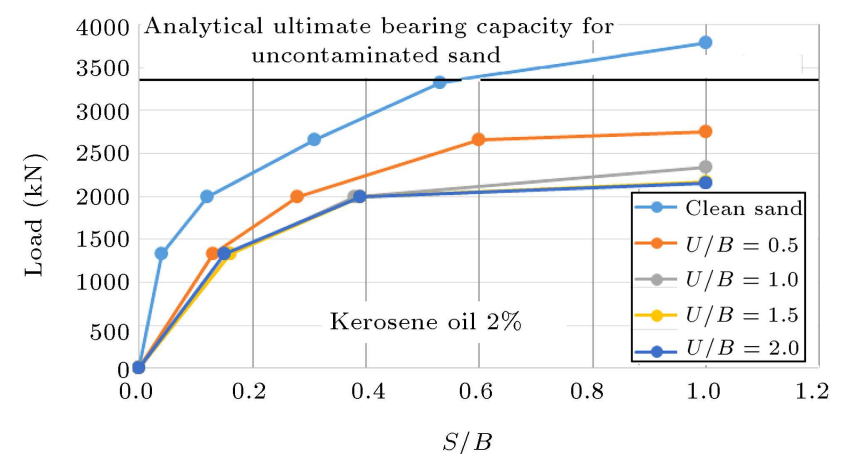

Figure 7. The load-settlement ratio curves of a circular foundation placed on a sandy soil contaminated with kerosene with different contamination depths obtained from laboratory results (contamination percentage $=2 \%$ ).

circular foundation placed on a soil contaminated with gas oil and kerosene. Settlement ratio is defined by the dimensionless ratio between foundation settlement and foundation width. Based on the experimental pieces of evidence, all types of failure were in the form of punching failure. Parameters $B, S$, and $U$ are defined as the footing width, foundation settlement, and contaminated layer thickness, respectively. In this case, the values of the bearing capacity and other contamination percentages are summarized in Tables 4 and 5. Contamination percentage is defined by the weight ratio between contamination and total soil weight. As can be seen, an increase in the thickness of the contaminated layer significantly decreases the bearing capacity of the foundation. This fact results in the friction reduction between soil particles in the foundation influence zone. Based on the results, it can be determined that the thickness of the contaminated layer considerably influences the bearing capacity of the sandy soil.

As the summarized results show the effects of the kerosene and gasoil contaminated layers on BCR

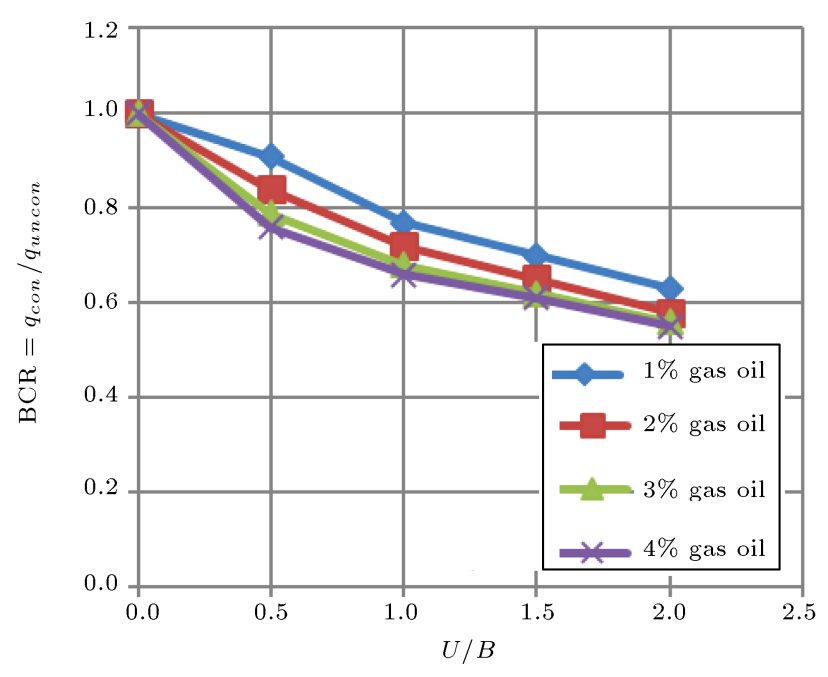

Figure 8. Bearing Capacity Ratio (BCR) changes with $U / B$ for soils contaminated with gasoil.

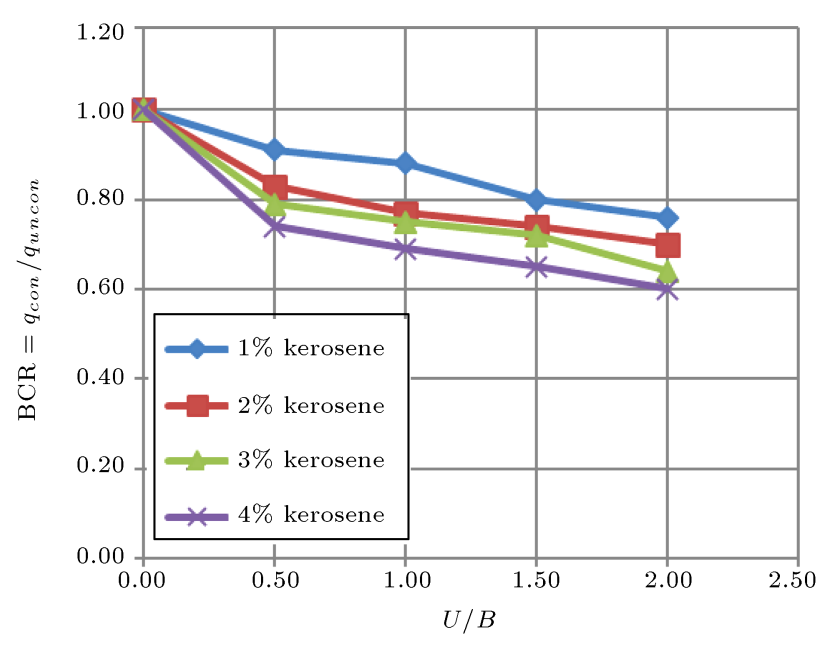

Figure 9. Bearing Capacity Ratio (BCR) changes with $U / B$ for soils contaminated with Kerosene oil.

parameters in Figures 8 and 9, these changes start from low $U / B$ ratios equal to 0.5 and 1 , resulting from the encounter between the contaminated soil layers and the failure zone placed under the foundation. In the $U / B$ values more than 1.0 , the slope of variation of BCR verses $U / B$ decreases dramatically. This fact represents the exit of the contamination from failure zone of the foundation.

\subsection{Studying the variation in the contamination percentage}

Figures 10 and 11 show the load-settlement curves for the circular foundation on the sandy soil contaminated with Gasoil and Kerosene obtained from laboratory results when the contamination ratio $U / B$ is constant in every case and equal to 0.5 in different contamination percentages of $0,1,2,3$, and 4 . In addition, the BCRs in this case and other contamination depth ratios are summarized in Tables 5 and 6 . 
Table 5. The Bearing Capacity Ratio (BCR) for the circular foundation placed on sandy soil contaminated with gasoil when the contamination depth and the contamination percentage are variable.

\begin{tabular}{clcccc}
\hline Series & \multicolumn{1}{c}{$\begin{array}{c}\text { Contamination } \\
\text { material }\end{array}$} & $\boldsymbol{U} / \boldsymbol{B}$ & $\begin{array}{c}\text { Contamination } \\
\text { percentage }\end{array}$ & $\begin{array}{c}\text { Bearing capacity } \\
(\mathbf{k P a})\end{array}$ & BCR \\
\hline CS & Uncontaminated sand & 0.0 & 0 & 482.80 & 1.00 \\
GO1-1 & Gas oil & 0.5 & 1 & 439.20 & 0.91 \\
GO2-1 & Gas oil & 0.5 & 2 & 405.55 & 0.84 \\
GO3-1 & Gas oil & 0.5 & 3 & 381.41 & 0.79 \\
GO4-1 & Gas oil & 0.5 & 4 & 366.93 & 0.76 \\
GO1-2 & Gas oil & 1.0 & 1 & 371.76 & 0.77 \\
GO2-2 & Gas oil & 1.0 & 2 & 347.62 & 0.72 \\
GO3-2 & Gas oil & 1.0 & 3 & 328.30 & 0.68 \\
GO4-2 & Gas oil & 1.0 & 4 & 318.65 & 0.66 \\
GO1-3 & Gas oil & 1.5 & 1 & 337.96 & 0.70 \\
GO2-3 & Gas oil & 1.5 & 2 & 313.89 & 0.65 \\
GO3-3 & Gas oil & 1.5 & 3 & 299.34 & 0.62 \\
GO4-3 & Gas oil & 1.5 & 4 & 294.51 & 0.61 \\
GO1-4 & Gas oil & 2.0 & 1 & 304.20 & 0.63 \\
GO2-4 & Gas oil & 2.0 & 2 & 280.02 & 0.58 \\
GO3-4 & Gas oil & 2.0 & 3 & 270.37 & 0.56 \\
GO4-4 & Gas oil & 2.0 & 4 & 265.54 & 0.55 \\
\hline
\end{tabular}

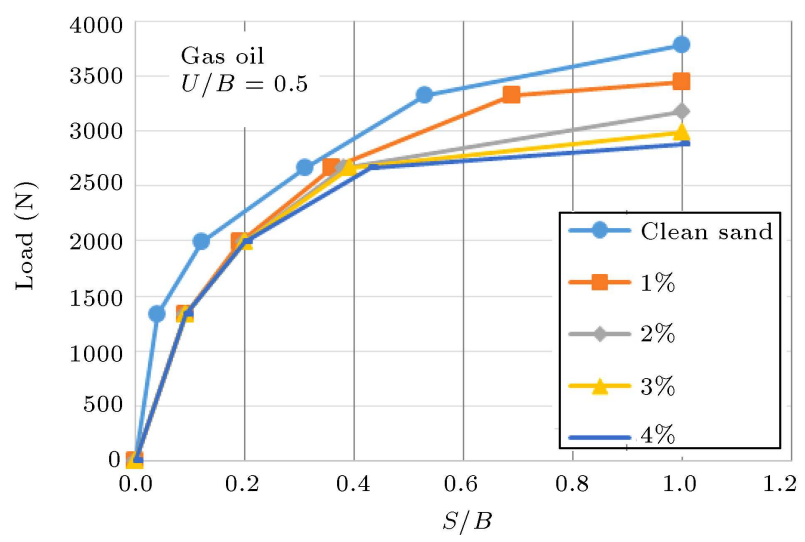

Figure 10. The load-settlement ratio curves of the circular foundation placed on the sandy soil contaminated with gasoil with different percentages obtained from experimental results $(U / B=0.5)$.

As can be seen, a sharp decrease in the ultimate bearing capacity is observed when the percentage of contamination increases. The reason for this decrease in bearing capacity can be associated with the decrease in Terzaqhi's bearing capacity coefficients $N_{\gamma}$ and $N_{c}$. In order to validate and compare the experimental results with analytical methods, load-bearing capacity can be calculated based on the specifications obtained from the laboratory according to the Terzaghi bearing capacity equation [16].

$$
q_{u}=0.5 B \gamma N_{\gamma}+c N_{c} .
$$

By considering the weight coefficient $\left(N_{\gamma}\right)$ equal to 36.5 , the cohesion coefficient $\left(N_{c}\right)$ equal to 52.6 , and

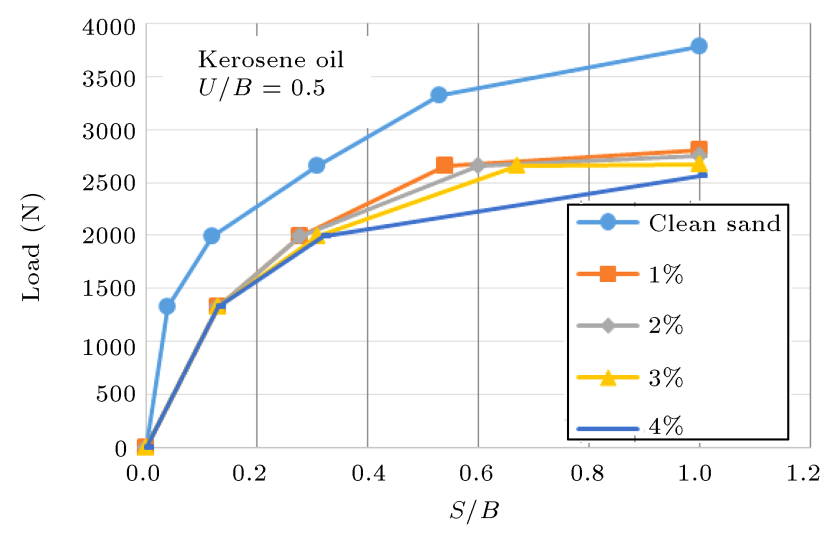

Figure 11. The load-settlement ratio curves of the circular foundation placed on the sandy soil contaminated with Kerosene with different percentages obtained from experimental results $(U / B=0.5)$.

the average specific wet unit weight of soil in the laboratory equal to $17.75 \mathrm{kN}$ per cubic meter, the bearing capacity of a circular foundation with a width of $10 \mathrm{~cm}$ on the uncontaminated sandy soil is equal to $440 \mathrm{kPa}$, which has an acceptable difference of $9 \%$ from the value obtained through the experimental tests. In the soils contaminated with kerosene and gas oil, when the contamination increases, the bearing capacity decreases due to changes in the parameters of cohesion and angle of internal friction. Thus, to calculate the bearing capacity of contaminated sandy soils, $N_{\gamma}$ and $N_{c}$ should be considered based on the contamination percentage and the contaminated layer thickness. 
Table 6. The Bearing Capacity Ratio (BCR) for the circular foundation placed on the sandy soil contaminated with Kerosene when the contamination depth and the contamination percentage are variable.

\begin{tabular}{clcccc}
\hline Series & $\begin{array}{c}\text { Contamination } \\
\text { material }\end{array}$ & $\boldsymbol{U} / \boldsymbol{B}$ & $\begin{array}{c}\text { Contamination } \\
\text { percentage }\end{array}$ & $\begin{array}{c}\text { Bearing capacity } \\
(\mathbf{k P a})\end{array}$ & BCR \\
\hline CS & Uncontaminated sand & 0.0 & 0 & 482.80 & 1.00 \\
KO1-1 & Kerosene oil & 0.5 & 1 & 357.90 & 0.74 \\
KO2-1 & Kerosene oil & 0.5 & 2 & 350.80 & 0.73 \\
KO3-1 & Kerosene oil & 0.5 & 3 & 340.80 & 0.71 \\
KO4-1 & Kerosene oil & 0.5 & 4 & 327.39 & 0.68 \\
KO1-2 & Kerosene oil & 1.0 & 1 & 339.36 & 0.70 \\
KO2-2 & Kerosene oil & 1.0 & 2 & 299.20 & 0.62 \\
KO3-2 & Kerosene oil & 1.0 & 3 & 284.40 & 0.59 \\
KO4-2 & Kerosene oil & 1.0 & 4 & 280.60 & 0.58 \\
KO1-3 & Kerosene oil & 1.5 & 1 & 311.20 & 0.64 \\
KO2-3 & Kerosene oil & 1.5 & 2 & 276.90 & 0.57 \\
KO3-3 & Kerosene oil & 1.5 & 3 & 270.30 & 0.56 \\
KO4-3 & Kerosene oil & 1.5 & 4 & 254.52 & 0.53 \\
KO1-4 & Kerosene oil & 2.0 & 1 & 286.00 & 0.59 \\
KO2-4 & Kerosene oil & 2.0 & 2 & 274.80 & 0.57 \\
KO3-4 & Kerosene oil & 2.0 & 3 & 268.70 & 0.56 \\
KO4-4 & Kerosene oil & 2.0 & 4 & 254.52 & 0.53 \\
\hline
\end{tabular}

\subsection{Studying the effect of the oil contamination type}

By keeping the other parameters constant, the effect of soil contamination on the foundation behavior can be determined. As shown in Tables 4 and 5, the highest influence of both pollutants in BCR is within $1 \%$ contamination and the $U / B$ ratio of 0.5 , which is compatible with Ahmed's results [12]. In this condition, a decrease in the BCR value for gasoil and Kerosene is equal to 13 and 19, respectively. Hence, it can be argued that a decrease in the soil strength and its ultimate bearing capacity are associated directly with the mechanical properties of soils, type of pollutant, and its percentage. On the other hand, based on the claims of other researchers, the ultimate bearing capacity depends on the viscosity of the pollutant, surrounding temperature, and chemical properties of the soil, which have not been addressed in this study. By comparing the results of the tests conducted on two types of pollutants, it can be determined that Kerosene is more effective in decreasing the strength and bearing capacity of the sandy soil.

According to the bearing capacities of the foundation in different percentages and contamination depths by using the TableCurve software, the following formulas have been presented to predict the bearing capacity of the circular foundation placed on the sand contaminated with Kerosene and gasoil.
The relations used for Kerosene:

$$
q_{\mathrm{ult}}(\mathrm{kPa})=\left(7242+\frac{1770.23}{X}+\frac{1770.23}{Y}\right) .
$$

The relations used for gasoil:

$$
q_{\mathrm{ult}}(\mathrm{kPa})=(15771-2575 X-643.7 Y) .
$$

In the above equations, $Y=U / B$, and $X$ and $\gamma$ represent the percentage of contamination and soil unit weight, respectively. Based on these equations and the information about the depth and percentage of contamination, one can predict the circular foundation bearing capacity.

\section{Conclusion}

This study investigated the bearing capacity of the circular foundation placed on sandy soil both in an uncontaminated state and contamination with gasoil and Kerosene oil with different percentages and depths. The following results are obtained.

The results achieved by the laboratory model showed that the increase of the contamination percentage and the depth of the soil contamination layer with both contaminators of gasoil and Kerosene oil decreased the circular foundation bearing capacities. The contamination of dry sand with more than $1 \%$ 
caused a dramatic decrease in bearing capacity. In these cases, at the contamination depth ratios equal to $0.5,1$, and 2 , the bearing capacity decreased by $12,20,25$, and $30 \%$ for gas oil and 25, 32, 39, and $40 \%$ for Kerosene oil, respectively. For more than $2 \%$ contamination and the $U>B$, the decrease of the bearing capacity is not significant.

The Bearing Capacity Ratios (BCR) showed that an increase in the contamination depth was more influential in decreasing the bearing capacity than that in the contamination percentage. By comparing the data associated with Kerosene and gasoil, it could be seen that the soil contaminated with Kerosene was more influential in decreasing the bearing capacity than that with gasoil. Finally, some formulas were provided based on which one can predict the bearing capacity factor of a circular foundation by knowing the depth and percentage of contamination. This final conclusion and the provided relations prevent time-consuming calculations and costly tests.

\section{References}

1. Kumar, J. "The variation of $\mathrm{Ng}$ with footing roughness using the method of characteristics", Int. J. Numer. Anal. Methods Geomech., 33(2), pp. 275-284 (2009).

2. Veiskarami, M., Jahanandish, M., and Ghahramani, A. "Prediction of the bearing capacity and load-displacement behavior of shallow foundations by stress-level-based ZEL method", Scientia Iranica, Sharif University of Technology Co-Published by Elsevier, Trans. A, 18(1), pp. 20-35 (2011).

3. Veiskarami, M., Kumar, J., and Valikhah, F. "Effect of the flow rule on the bearing capacity of strip foundations on sand by the upper-bound limit analysis and slip lines", Int. J. Geomech., ASCE, 14(3), pp. 04014008-1-04014008-11 (2014).

4. Bolton, M.D. and Lau, C.K. "Vertical bearing capacity factors for circular and strip footings on MohrCoulomb soil", Can. Geotech. J., 30(6), pp. 1024-1033 (1993).

5. Evgin, E. and Das, B.M. "Mechanical behavior of an oil contaminated sand", Proc., Mediterranean Conf., Usmen and Acar, Eds., Balkema, Rotterdam, The Netherlands, pp. 101-108 (1992).

6. Al-Sanad, H.A., Eid, W.K., and Ismael, N.F. "Geotechnical properties of oil-contaminated Kuwaiti sand", J. Geotech. Engrg., 121(5), pp. 407-412 (1995).

7. Al-Sanad, H.A. and Ismael, N.F. "Aging effects on oil contaminated Kuwaiti sand", J. Geotech. Geoenviron. Eng., 123(3), pp. 290-293 (1997).

8. Shin, E.C., Lee, J.B., and Das, B.M. "Bearing capacity of a model scale footing on crude oil contamination sand", Geotech. Geo. Eng. J., 17(2), pp. 123-132 (1999).
9. Shin, E.C. and Das, B.M. "Bearing capacity of unsaturated oil-contaminated sand", Int. J. Offshore Polar Eng., 11(3), pp. 220-227 (2001).

10. Shin, E.C., Omar, M.T., Tahmaz, A.A., and Das, B.M. "Shear strength and hydraulic conductivity of oil-contaminated sand", Proc., 4th Int. Congress on Environmental Geotechnics, Rio de Janeiro, Brazil, Balkema, 1, pp. 9-13 (2002).

11. Khamechiyan, M., Charkhabi, A.H., and Tajik, M., The Effects of Crude Oil Contamination on Geotechnical Properties of Bushehr Coastal Soils in Iran, The Geological Society of London, IAEG2006 Paper number 214 (2007).

12. Nasr, A.M. "Experimental and theoretical studies for the behavior of strip footing on oil-contaminated sand", Journal of Geotechnical and Geoenvironmental Engineering, 135(12), pp. 1814-1822 (2009).

13. Abousnina, R.M., Manalo, A., Shiau, J., and Lokuge, W. "Effects of light crude oil contamination on the physical and mechanical properties of fine sand", Soil and Sediment Contamination: An International Journal, 24(8), pp. 833-845 (2015).

14. Nasr, A.M. "Behaviour of strip footing on oilcontaminated sand slope", International Journal of Physical Modelling in Geotechnics, 16(3), pp. 134-151 (2015).

15. Briaud, J.L. and Jeanjean, P. "Load settlement curve method for spread footings on sand", Journal of Geotechnical and Geoenvironmental Engineering, ASCE, 133(8), pp. 905-920 (1994).

16. Das, B.M., Principles of Geotechnical Engineering, 3rd Ed., PWS Publishing Company, p. 436 (1994).

\section{Biographies}

Seyyed Akbar Abtahi received her BSc degree in Civil Engineering from Tabriz University, Tabriz, Iran, in 1995. He is a student of MSc degree in Geotechnical Engineering in Estahban Islamic Azad University. His field of study is contaminated soil.

Alireza Hajiani Boushehrian received his BSc, MSc, and $\mathrm{PhD}$ degrees in Civil Engineering (Soil Mechanics and Foundations) from Shiraz University in 2002, 2004, and 2010, respectively. He is now an Assistant Professor at the Department of Civil Engineering, School of Engineering, Islamic Azad University in Shiraz, Siraz, Iran. He has participated in writing and reviewing a number of papers published in refereed journals and conference proceedings in the reinforced soil and foundation engineering. His research interests are dynamic and cyclic experimental modeling, dam engineering, and numerical methods. 